\title{
THE
}

\section{Estimation of Uncertainty in Air-Water Exchange Flux 2 and Gross Volatilization Loss of PCBs: a Case Study 3 based on Passive Sampling in the Lower Great Lakes}

Ying Liu

Siyao Wang

Carrie A. McDonough

Mohammed Khairy

Derek Muir

Follow this and additional works at: https://digitalcommons.uri.edu/gsofacpubs

The University of Rhode Island Faculty have made this article openly available.

Please let us know how Open Access to this research benefits you.

This is a pre-publication author manuscript of the final, published article.

Terms of Use

This article is made available under the terms and conditions applicable towards Open Access Policy Articles, as set forth in our Terms of Use.

\section{Citation/Publisher Attribution}

Liu, Y., Wang, S., McDonough, C. A., Khairy, M., Muir, D., \& Lohmann, Rainer. (2016). Estimation of Uncertainty in Air--Water Exchange Flux and Gross Volatilization Loss of PCBs: A Case Study Based on Passive Sampling in the Lower Great Lakes. Environmental Science \& Technology, 50(20), 10894-10902. Available at: http://pubs.acs.org/doi/abs/10.1021/acs.est.6b02891

This Article is brought to you for free and open access by the Graduate School of Oceanography at DigitalCommons@URI. It has been accepted for inclusion in Graduate School of Oceanography Faculty Publications by an authorized administrator of DigitalCommons@URI. For more information, please contact digitalcommons-group@uri.edu. 


\section{Authors}

Ying Liu, Siyao Wang, Carrie A. McDonough, Mohammed Khairy, Derek Muir, and Rainer Lohmann 
1 Estimation of Uncertainty in Air-Water Exchange Flux

2 and Gross Volatilization Loss of PCBs: a Case Study

3 based on Passive Sampling in the Lower Great Lakes.

4

5 YING LIU ${ }^{\dagger, \ddagger, *}$, SIYAO WANG ${ }^{\dagger}$, CARRIE A. MCDONOUGH ${ }^{\ddagger}$, MOHAMMED KHAIRY $^{\ddagger}, \phi$,

6 DEREK MUIR ${ }^{\S}$, RAINER LOHMANN $^{\ddagger *}$

7

8

${ }^{\dagger}$ State Key Laboratory of Pollution Control and Resource Reuse, Shanghai Key Lab of Chemical Assessment and Sustainability, College of Environmental Science and Engineering, Tongji University, Shanghai 200092, China.

${ }^{\ddagger}$ Graduate School of Oceanography, University of Rhode Island, Narragansett,

E-mail address: rlohmann@mail.uri.edu (R. Lohmann), Phone: 401-874-6612,

Fax: 401-874-6811; liu_ying@tongji.edu.cn (Y. Liu). 


\section{ABSTRACT}

Compared with dry and wet deposition fluxes, air-water exchange flux cannot be directly measured experimentally. Its model-based calculation contains considerable uncertainty because of uncertainties in input parameters. To capture inherent variability of air-water exchange flux of PCBs across the lower Great Lakes and calculate their annual gross volatilization loss, 57 pairs of air and water samples from 19 sites across Lakes Erie and Ontario were collected using passive sampling technology during 2011-2012. Error propagation analysis and Monte Carlo simulation were applied to estimate uncertainty in the air-water exchange fluxes. Results from both methods were similar, but error propagation analysis estimated smaller uncertainty than Monte Carlo simulation in cases of net deposition. Maximum likelihood estimations (MLE) on wind speed and air temperature were recommended to quantify the site-specific air-water exchange flux. An assumed 30-40\% of relative uncertainty in overall air-water mass transfer velocity was confirmed. MLEs on volatilization fluxes of total PCBs across Lakes Erie and Ontario were $0.78 \mathrm{ng} \mathrm{m}^{-2}$ day $^{-1}$ and $0.53 \mathrm{ng} \mathrm{m}^{-2}$ day $^{-1}$, respectively, and gross volatilization losses of total PCBs over the whole lakes were $74 \mathrm{~kg} \mathrm{year}^{-1}$ for Lake Erie and $63 \mathrm{~kg}_{\text {year-1 }}$ for Lake Ontario. Mass balance analysis across Lake Ontario indicated that volatilization was an uppermost loss process of aqueous PCBs. 


\section{INTRODUCTION}

Polychlorinated biphenyls (PCBs) are a class of persistent toxic chemical substances of concern in the Great Lakes. ${ }^{1-3}$ Atmospheric deposition was considered as a significant source of PCBs to the lower Great Lakes, including dry deposition, wet deposition and air-water diffusive fluxes. ${ }^{4,5}$ Atmospheric processes accounted for $80-90 \%$ of total loadings of PCBs to the oceans and $65 \%$ of total atmospheric deposition of PCBs was attributed to gas transfer. ${ }^{6}$ Results from Lake Superior revealed that volatilization was a major loss process of PCBs from water column and gross volatilization loss of PCBs was $250 \mathrm{~kg}_{\text {year-1 }}$ for $^{-}$ 1992. ${ }^{7}$ Across Lakes Erie and Ontario, net volatilization from lake waters was still a primary trend of PCB gas exchange process in our previous work. ${ }^{8}$ In previous publications, air-water exchange fluxes of PCBs had been estimated, but with limited knowledge on its uncertainty, 6, 7, 9-11 especially involving variations of the flux over time and space.

Compared with dry and wet deposition fluxes, air-water (diffusive) exchange flux cannot be directly measured experimentally and its calculation (based on a two-film diffusion model) involves air vapor and freely-dissolved water concentrations, air-water partitioning and air-water mass transfer coefficients of PCBs. ${ }^{10,12,13}$ The gaseous and freely-dissolved PCBs are not bound to particulates by definition, and the filtered air or water in active sampling is only operationally defined as gaseous or dissolved, as any particles penetrating the filters are also included. ${ }^{14,15}$ By contrast, passive sampling is an ideal technology for air-water exchange flux measurements, because it specifically captures the gaseous and freely-dissolved fractions, avoiding the filter bias. ${ }^{11}$ Nonetheless, passive sampling contains uncertainties from PCB analysis and model coefficients, which 
propagate in the air-water exchange flux calculations.

Error propagation analysis is a common method to estimate flux uncertainty, and many researchers have applied this method to quantify the uncertainty, e.g., in the Lakes Erie and Ontario,, 816 in the Lake Superior, ${ }^{16,17}$ in the Chesapeake Bay, ${ }_{14}$ in Taiwanese coasts, ${ }^{18,19}$ and in East China Sea. ${ }^{20}$ These studies assumed relative uncertainties of approximately $50 \%$ for Henry's law constants, around 30-40\% for air-water mass transfer velocities of PCBs and a normal distribution of the flux. But the flux does not always follow a normal distribution (see below) because not all of uncertainties in model parameters (e.g., wind speed and air-water transfer velocity of PCBs) contain a random error. An alternative method is the use of Monte Carlo simulations. The technique can quantify the effect of uncertainty from varying parameters on model result. ${ }^{21}$ Venier and Hites estimated total net mass transfer rates of PBDEs to the Great Lakes and their relative errors using the simulations; however, the calculated results were based on only one to five samples per lake and variables were assumed to follow a normal distribution. ${ }^{22}$ Qin et al. fitted probability distribution of variables by normal or lognormal distribution functions, but ignored their potential correlations (e.g., between gaseous and aqueous concentrations). ${ }^{15}$ To our knowledge, few studies have evaluated the uncertainty and parameter sensitivity in air-water exchange flux of PCBs via Monte Carlo simulation. Furthermore, many studies estimated uncertainty in the flux based on only a few sampling sites due to limited deployments, $7,17,18$ yet atmospheric and aqueous concentrations of PCBs and meteorology situation are significantly varying over time and space, ${ }^{8}$ resulting in temporal and spatial variations of air-water exchange flux across the whole lakes and enormous uncertainty in annual gas 
transfer loadings of PCBs. This prompted us to comprehensively estimate overall uncertainty in air-water exchange flux of PCBs across the lakes.

To capture the inherent variation in air-water exchange of PCBs, a case study across Lakes Erie (31 pair air and water samples from 9 sampling sites) and Ontario (26 pairs from 10 sites) was performed based on passive sampling during 2011-2012.8, 23 Error propagation analysis and Monte Carlo simulation were conducted to estimate uncertainty in air-water exchange flux of PCBs. The aim of this study includes 1) estimating uncertainty in air-water exchange equilibrium of PCBs, 2) comparing results from both methods, and 3) evaluating uncertainty in air-water exchange fluxes and annual gross volatilization loss of PCBs across both lakes.

\section{MATERIALS AND METHODOLOGY}

Passive sampling and chemical analysis. The information on sampling sites, low density polyethylene (LDPE) deployment in air and water, chemical analysis methodologies and preparation of the LDPE passive samplers, quality assurance and quality control were described elsewhere. ${ }^{8}$ Briefly, the LDPE membranes were spiked with performance reference compounds, and deployed in the air and water of Lakes Erie and Ontario. In this study, uncertainty in air-water exchange flux of PCBs was estimated based on 57 pair samples (air and water) collected during 2011-2012, nine sites from Lake Erie and ten sites from Lake Ontario, as shown in Figure S1. After collection, LDPE samples were spiked with surrogate standards $\left({ }^{13} \mathrm{C}\right.$ labeled PCBs), extracted and cleaned up if needed. 29 PCB congeners (CB 8, 11, 18, 28, 44, 52, 66, 77, 81, 101, 105, 114, 118, 123, 126, $128,138,153,156,157,167,169,170,180,187,189,195,206,209)$ were 
analyzed using GC-MS/MS. Procedural blanks, field blanks, matrix spikes, and duplicate samples were involved in the analysis. Limits of detection, recoveries and relative standard deviations of target PCBs were reported elsewhere. ${ }^{8}$ The related meteorological data are presented in Table S1.

Air-water fugacity ratio. The fugacity ratio $\left(f_{\mathrm{a}} / f_{\mathrm{w}}\right)$ is normally calculated from atmospheric and aqueous concentrations of PCBs $\left(\mathrm{C}_{\mathrm{a}}\right.$ and $\mathrm{C}_{\mathrm{w}}$, both in $\left.\mathrm{pg} \mathrm{m}^{-3}\right)$ and (air) temperature-corrected partitioning coefficient between air and water ( $K_{\text {aw }}$, as shown in Equation 1.

$$
\log \left(\frac{f_{a}}{f_{w}}\right)=\log \left(\frac{C_{a}}{C_{w} \times K_{a w}}\right)
$$

Based on the LDPE passive sampling technology, ${ }^{24}$ the atmospheric and aqueous concentrations $\left(\mathrm{C}_{\mathrm{a}}\right.$ and $\left.\mathrm{C}_{\mathrm{w}}\right)$ can be calculated according to equilibrium concentrations of PCBs measured in the deployed LDPE sheets (based on LDPE volume) and partitioning coefficients between LDPE and air or water (K $\left.K_{\mathrm{PE}-\mathrm{a}(\mathrm{w})}\right)$, as presented in Equation 2. Hence, the fugacity ratio depends only on the equilibrium concentrations of PCBs in LDPE matrix (deployed in air and water), as shown in Equation 3.

$$
\begin{gathered}
\mathrm{C}_{\mathrm{a}(\mathrm{w})}=\frac{C_{P E}}{\% e q u(a / w) \times K_{\mathrm{PE}-\mathrm{a}(\mathrm{w})}} \\
\log \left(\frac{f_{a}}{f_{w}}\right)=\log \left(\frac{c_{a}}{C_{w} \times K_{a w}}\right)=\log \left(\frac{C_{P E(a)}}{\% e q u(a) \times K_{P E-a}} \times \frac{\% \text { equ }(w) \times K_{P E-w}}{C_{P E(w)} \times K_{a w}}\right)=\log \left(\frac{C_{P E(a)}}{C_{P E(w)}} \times \frac{\% e q u(w)}{\% e q u(a)}\right)
\end{gathered}
$$
where \%equ is the predicted percent equilibrium (for more detail see the SI). Air-water exchange flux. The flux $\left(F_{a / w}\right.$, in $\left.\mathrm{pg} \mathrm{m}^{-2} \mathrm{day}^{-1}\right)$ is commonly calculated from overall air-water mass transfer velocity $\left(v_{a / w}\right.$, in $\left.\mathrm{m} \mathrm{day}^{-1}\right)$ and the concentration difference between water and air $\left(C_{w}{ }^{-} C_{a} / K_{a w}\right)$ as in Equation $4,{ }^{10,17}$ where $K_{a w}$ is air-water partitioning coefficient corrected by (air) temperature.

$$
F_{\mathrm{a} / \mathrm{w}}=v_{\mathrm{a} / \mathrm{w}} \times\left(C_{\mathrm{w}}-C_{\mathrm{a}} / K_{\mathrm{aw}}\right)
$$


$K_{\text {aw }}$ is determined as Equation 5, where $H_{c}$ is Henry's law constant (in atm L $\left.\mathrm{mol}^{-1}\right), R$ is the gas constant $\left(0.08206\right.$ in atm $\left.\mathrm{L} \mathrm{mol}^{-1} \mathrm{~K}^{-1}\right)$, and $T$ is the absolute temperature in Kelvin. $H_{c}$ values were obtained from Khairy et al. ${ }^{25}$

$$
K_{a w}=\frac{H_{c}}{R \times T}
$$

Overall mass transfer velocity $\left(v_{\mathrm{a} / \mathrm{w}}\right)$ was calculated based on a modified two-film air-water exchange model, ${ }^{10}$ equated as follows,

$$
\frac{1}{v_{a / w}}=\frac{1}{v_{w}}+\frac{1}{K_{a w} \times v_{a}}
$$

where $v_{\mathrm{a}}$ and $v_{\mathrm{w}}$ are the air-side and water-side transfer velocities of target compound, respectively. They are a function of the molecular diffusivity of the target compound in air or water and stability-dependent turbulent diffusivity (wind speed).10

Error propagation analysis. In order to estimate the uncertainty in air-water fugacity ratio and the calculated diffusive flux using statistical techniques, measured uncertainties in air and water analysis, air-water partitioning coefficients (including Henry's law constant and temperature) and overall mass transfer velocity were considered.

There are four variables with random uncertainty for the fugacity ratio based on Equations 1 and 5, for which the error propagation is given in Equation 7. With regard to the passive sampling technology, four variables are involved (see Equation 3); its error propagation is detailed in Equation 8. Relative uncertainty of percent equilibrium was estimated in the Supporting Information and ranges from $0 \%$ to $51 \%$ (Table S2),

$$
\delta \log \left(\frac{f_{a}}{f_{w}}\right)=\sqrt{\left(\frac{\delta C_{a}}{C_{a}}\right)^{2}+\left(\frac{\delta C_{w}}{C_{w}}\right)^{2}+\left(\frac{\delta H_{c}}{H_{c}}\right)^{2}+\left(\frac{\delta T}{T}\right)^{2}}
$$




$$
\delta \log \left(\frac{f_{a}}{f_{w}}\right)=\sqrt{\left(\frac{\delta C_{P E(a)}}{C_{P E(a)}}\right)^{2}+\left(\frac{\delta C_{P E(w)}}{C_{P E(w)}}\right)^{2}+\left(\frac{\delta \% \text { equilibrium }(a)}{\% \text { equilibrium }(a)}\right)^{2}+\left(\frac{\delta \% \text { equilibrium }(w)}{\% \text { equilibrium }(w)}\right)^{2}}(8)
$$
Equation 4 and 5, yielding the following:

$$
\frac{\delta F}{F}=\sqrt{\left(\frac{\delta v_{a / w}}{v_{a / w}}\right)^{2}+\left(\frac{v_{a / w} C_{a} R T}{F H_{c}} \frac{\delta H_{c}}{H_{c}}\right)^{2}+\left(\frac{v_{a / w} C_{a} R}{F H_{c}} \delta T\right)^{2}+\left(\frac{v_{a / w} R T}{F H_{c}} \delta C_{a}\right)^{2}+\left(\frac{v_{a / w}}{F} \delta C_{w}\right)^{2}}
$$

The relative standard deviations (RSD) of atmospheric and aqueous concentrations $\left(\frac{\delta C_{a}}{C_{a}}\right.$ and $\left.\frac{\delta C_{w}}{C_{w}}\right)$ are associated with the analysis and obtained from Table S2. A value of $30 \%$ and $50 \%$ was assumed for RSDs in $v_{a / w}$ and $H_{c}$, respectively, after Rowe and Perlinger. ${ }^{17}$ The standard deviation $(\delta)$ in T was calculated based on the NOAA National Data Buoy Center historical archives (www.ndbc.noaa.gov). A detailed description of error propagation analysis is presented in the Supporting Information.

Monte Carlo simulation. This was performed for the overall air-water mass transfer velocity $\left(v_{a} / w\right)$ and air-water exchange flux $\left(F_{a / w}\right)$ of PCBs for each sample pair. The general method is to quantifiy uncertainty associated with incomplete data (e.g., wind speed, ambient temperature, atmospheric and aqueous PCB concentrations) by model-fitting probability distribution functions (PDF) of the incomplete data that are used as input to Monte Carlo simulations. We fitted fourteen available PDFs to derive the best-fit PDF of site-specific ambient parameters. The best-fit PDFs and probability charts were used to generate a set of random values for input parameters. As variables in the system being modeled are often inter-dependent, we defined correlations between ambient temperature and wind speed based on pairs of measured data. Normal 
distributions with specified ranges were assumed for other parameters, including atmospheric and aqueous PCB concentrations and Henry's law constants of PCBs. Standard deviation of the PCB concentrations were set to the product of average relative standard deviation and site-specific PCB concentrations. Relative uncertainty in $H_{c}$ was assumed as $50 \%$ after Blanchard et al. and Rowe et al. ${ }^{17,26}$ Finally, Monte Carlo simulations were applied for the estimation of air-water exchange of PCBs across the whole lakes over time and place. Passive sampling data from 2011-2012 was used to construct PDFs of gaseous and freely-dissolved PCB concentrations across Lakes Erie and Ontario. Meteorological data from open lake sites were selected as representative air temperatures and wind speeds. Correlations between variables were carefully defined based on the monitoring data, including between atmospheric and aqueous concentrations and between PCB congeners. In each simulation, a total of $10^{5}$ trials were generated to obtain sufficient data to estimate probability distributions of $v_{\mathrm{a} / \mathrm{w}}$ and $F_{a / w}$. All simulations were performed using Oracle Crystal Ball R11.1 software packages. More details are presented in the Supporting Information.

Gross volatilization loss and mass balance of PCBs. Gross volatilization losses of PCBs across Lakes Erie and Ontario were calculated as the product of lake area and arithmetic mean of air-water exchange flux. Input (river inflows and precipitation) and output (river outflow and volatilization loss) of freely-dissolved PCBs into and from Lake Ontario were calculated for construction of whole lake mass balance. (see the Supporting Information for details). 


\section{RESULTS AND DISCUSSION}

Estimation of air-water exchange equilibrium of PCBs. Most semi-volatile organic pollutants (e.g. PCBs) have the potential to migrate between air and water phases. The fugacity gradient of chemicals is a mathematical expression that describes the direction in which chemicals diffuse, or are transported between environmental compartments. ${ }^{27-29}$ Fugacity is identical to partial pressure in ideal gases and is logarithmically related to chemical potential. Air-water fugacity ratios have been widely employed to determine net deposition $\left(f_{\mathrm{a}} / f_{\mathrm{w}}>1\right)$, net volatilization $\left(f_{\mathrm{a}} / f_{\mathrm{w}}<1\right)$, and equilibrium situation $\left(f_{\mathrm{a}} / f_{\mathrm{w}}=1\right)$ in many works. ${ }^{9}, 25,30-33$ However, it is crucial to distinguish equilibrium from non-equilibrium situations in such multi-compartment exchange. ${ }^{34}$ The range of fugacity ratios not significantly different from equilibrium can be estimated based on their uncertainty. 9, 35, 36 Uncertainty ranges of water-air exchange were calculated from Equations 7 and 8, respectively. Air-water fugacity ratios and the equilibrium ranges of selected PCBs are illustrated in Figure 1. Fugacity ratios were widely distributed, ranging from deposition to volatilization. It is challenging to accurately divide them into equilibrium and non-equilibrium situations. As for lighter PCBs (for example CB 28 and 52), the equilibrium ranges based on Equation 8 were more narrow than those based on Equation 7. For active sampling (i.e., a direct measurement of atmospheric and aqueous concentrations which is considered here as a theoretical comparison), relative uncertainty (RU) in atmospheric and aqueous concentrations, ambient temperature and Henry's law constant were considered, as shown in Equation 7. In this study, $0.29<f_{\mathrm{a}} / f_{\mathrm{w}}<3.47$ (or RU in $\log \left(f_{\mathrm{a}} / f_{\mathrm{w}}\right)=$ 0.54) were considered to not significantly differ from phase equilibrium. The 
result is similar with previous reports, in which an equilibrium window $0.3<$ $f_{\mathrm{a}} / f_{\mathrm{w}}<3.0$ were accepted by Lammel et al., ${ }^{35}$ Lin et al.,20 Mulder et al., ${ }^{32}$ Zhong et al., ${ }^{31,37}$ Castro-Jimenez et al., ${ }^{30}$ and Lohmann et al. ${ }^{36}$ In the passive sampling technique (see Equation 8), percent equilibrium reached (\%equilibrium) replaces $H_{\mathrm{c}}$ and temperature. The \%equilibrium depends on deployment time and turbulence in the environmental matrix. For lighter PCBs, the RUs in \%equilibrium were lower, as congeners equilibrated in the field $(\sim 100 \%$ of \%equilibrium), whereas for heavier PCBs, the RUs in \%equilibrium reached up to $51 \%$, as those congeners attained $<20 \%$ of \%equilibrium (see Table S2). For dichlorobiphenyl, the RU in $\log \left(f_{\mathrm{a}} / f_{\mathrm{w}}\right)$ reduced from 0.54 (Equation 7$)$ to 0.26 (namely $0.55<f_{\mathrm{a}} / f_{\mathrm{w}}<1.82$, for Equation 8). It reveals the advantage of the passive sampling technique in estimating non-equilibrium situation of air-water exchange of lighter PCBs. With regard to the congeners heavier than tetrachlorobiphenyl, however, the advantage gradually disappears because of greater RU in \%equilibrium, as shown in Table S2. Generally speaking, across the lower Great Lakes, net volatilization of PCBs from water to air was a primary trend in most cases (accounting for 53-78\% of total samples), except for CB 118 and 180.

Meanwhile, the probability of deposition or volatilization was also computed via Monte Carlo simulation in this study (as discussed in the following section). Table 1 lists air-water fugacity ratios and confidence levels of net deposition or volatilization of 7 selected PCBs for a specific sample (deployed at the Cape Vincent site in 2012 autumn). If a probability value was greater than $90 \%$ (hence tail probability was less than $10 \%$ ), we were quite confident of air-water exchange direction. As shown in Table 1, the estimation of air-water exchange 
direction based on Monte Carlo simulation are comparable or identical with those from the uncertainties in air-water fugacity ratios. Consequently, the Monte Carlo simulation further supports that the air-water fugacity ratios with uncertainty analysis based on the LDPE passive sampling technology is a simple and credible tool in estimating direction of air-water exchange of PCBs.

Effect of parameterization on air-water exchange flux. The flux $\left(F_{a / w}\right)$ is related to many parameters, including overall air-water mass transfer velocity $\left(v_{a} / w\right)$ and concentration difference in the water and air $\left(C_{w}-C_{a} / K_{a w}\right)$. Overall the transfer velocity depends on wind speed and temperature in the Whitman two-film model. ${ }^{10,12}$ The air-water partitioning coefficient $\left(K_{\mathrm{aw}}\right)$ of compounds of interest was calculated based on the Henry's law constant $\left(H_{\mathrm{c}}\right)$ and ambient temperature $(T)$. Hence, it is necessary to explore the effect of parameterization on air-water exchange flux.

We compared the difference of two parametric methods on ambient temperature and wind speed, i.e., arithmetic mean and maximum likelihood estimation (MLE) from best-fit probability distribution function (PDF). Probability distributions of ambient temperature, wind speed, overall mass transfer velocity, and air-water exchange flux from the Monte Carlo simulation are illustrated in Figure 2. Ambient temperatures followed a Weibull distribution (see Figure 2.b), and average temperature $\left(13.56^{\circ} \mathrm{C}\right)$ was close to its MLE $\left(14.36^{\circ} \mathrm{C}\right)$ from best-fit PDF. Wind speeds followed a lognormal distribution (see Figure 2.c), and average wind speed (5.14 $\left.\mathrm{m} \mathrm{s}^{-1}\right)$ was much greater than its MLE $\left(2.89 \mathrm{~m} \mathrm{~s}^{-1}\right)$. The $v_{a / w}$ is a piecewise function of wind speed after Schwarzenbach et al. ${ }^{10}$ In this case, arithmetic mean and MLE of wind speed were in different sub-domains, leading to a great difference in the $v_{a}$ values, as marked in Figure 
2.d. The probability distribution pattern of $F_{a / w}$ was similar to that of $v_{a / w}$. Both of them have a sharp peak with a large tail. MLEs of the $F_{a / w}\left(0.62 \mathrm{ng} \mathrm{m}^{-2} \mathrm{day}^{-1}\right)$ and the $v_{a / w}\left(19 \mathrm{~cm} \mathrm{day}^{-1}\right)$ are close to the model calculated values based on MLEs of temperature and wind speed (see Figure 2.a and d). However, the $F_{a / w}$ value (1.77 $\mathrm{ng} \mathrm{m}^{-2}$ day $\left.^{-1}\right)$ and the $v_{a} w$ value $\left(53 \mathrm{~cm} \mathrm{day}^{-1}\right)$ calculated from arithmetic mean (in the large tail) were $\sim 2.5$ times greater than the MLE values. Hence, the MLEs of meteorological parameters are recommended according to the probability distributions of $v_{a / w}$ and $F_{a / w}$. Due to the assumption that PCB concentrations in air and water followed a normal distribution with limited relative uncertainties (11-53\%), uncertainty in $F_{a / w}$ in the non-equilibrium situation depended mainly on the uncertainty in $v_{a / w}$. Consequently, the parametrization of ambient temperature and wind speed needs to be carefully evaluated when computing the air-water exchange flux of PCBs.

For most samples in this study, probability distribution patterns of meteorological data are similar to the above case (see Table S1). Briefly, temperature data followed a Weibull, Beta, or normal distribution, and in most cases MLE was close to its arithmetic mean. In contrast, wind speed data followed a lognormal distribution; the arithmetic mean likely overestimated wind speed and hence the air-water exchange flux. This applies both to daily sampling (as in active) as well as monthly samples (as in passive sampling).

\section{Estimation of uncertainty in air-water exchange flux. The air-water} exchange flux was quantified based on the two-film transfer model and relevant monitoring data. Uncertainties are inherent in measured data due to measurement limitations of PCB concentrations in air and water (e.g., sampling uncertainty and instrument precision) and temporal variations of wind speed 
and ambient temperature, which propagate to the calculated flux. Since uncertainty calculations are based on statistics, there are different ways to determine overall uncertainty. In this study, we applied two methods to estimate the uncertainty in air-water exchange flux, i.e., error propagation analysis and Monte Carlo simulation.

$$
\text { Uncertainty in overall air-water mass transfer velocity. The transfer velocity of }
$$
PCBs in air-water exchange was calculated with piecewise functions of wind speed in the two-film model. Error propagation analysis failed to capture the effect of uncertainty in wind speed on the uncertainty in the transfer velocity. In other studies, RSD of the transfer velocity were selected as $30 \%$ or $40 \%{ }^{17,19,} 26,38$ In this study, we estimated the uncertainty in $\left(v_{\mathrm{a}} / \mathrm{w}\right)$ via Monte Carlo simulation. In Figure 2.d, a peak range (baseline width of peak) of $v_{\mathrm{a}} / \mathrm{w}$ value is defined as a confidence interval with a specific certainty or a range of values that act as good estimate on the $v_{\mathrm{a} / \mathrm{w}}$. In this case, the $47.7 \%$ confidence interval of the $v_{\mathrm{a} / \mathrm{w}}$ is 12-25 cm day ${ }^{-1}$ with MLE of $19 \mathrm{~cm} \mathrm{day}^{-1}$.

In the fourteen selected samples across Lakes Erie and Ontario (see Figure S2), uncertainty results of $v_{\mathrm{a} / \mathrm{w}}$ from Monte Carlo simulation are similar to an assumed $30 \%$ of relative uncertainty (RU). In most cases, MLEs of $v_{\mathrm{a} / \mathrm{w}}$ from Monte Carlo simulation (red open squares) are close to mode values based on MLEs of wind speed and temperature (blue open circles). Moreover, peak ranges from Monte Carlo simulation are similar to those with $30 \%$ of RU in $v_{\mathrm{a} / \mathrm{w}}$.

Certainties in these peak ranges are $46 \%-78 \%$ in these samples. Therefore, it is reasonable to select $30-40 \%$ as the $\mathrm{RU}$ in $v_{\mathrm{a} / \mathrm{w}}$.

Uncertainty in air-water exchange flux. The uncertainty was estimated quantitatively by Monte Carlo simulation, and Figure 2.a presents probability 
distribution of air-water exchange flux of $\Sigma_{7} \mathrm{PCBs}$ as an example. The probability distribution follows a sharp peak with a large tail towards larger values (right side). The large tailing mostly resulted from the lognormal probability distribution of wind speed data. The flux range between $10 \%$ and $90 \%$ percentiles covered a wide range of $0.36-5.1 \mathrm{ng} \mathrm{m}^{-2}$ day $^{-1}$. However, the baseline

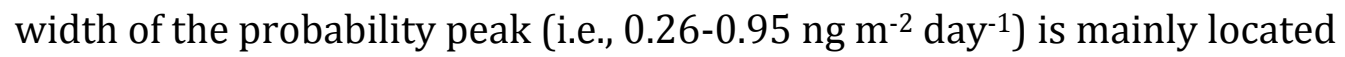
between the percentiles of $10 \%-50 \%$. Even the middle $40 \%$ estimation of the flux (i.e., $0.56-2.1 \mathrm{ng} \mathrm{m}^{-2}$ day $^{-1}$ for $30-70 \%$ estimation) overestimated the peak range of the flux. Therefore, the peak range can be defined as a good estimation range of the flux in this case, namely $0.26-0.95 \mathrm{ng} \mathrm{m}^{-2}$ day $^{-1}$ with a $46.8 \%$ confidence level.

Meanwhile, error propagation analysis was also applied to determine uncertainty in the flux, based on the above conclusion that the $30 \%$ of RU in $v_{\mathrm{a}} / \mathrm{w}$ is reasonable approximation. The results from both methods for the fourteen selected samples are compared pair-wise and summarized in Figure 3. Best estimate values (open) of the flux were comparable and close to each other. Yet the good estimation ranges of air-water exchange fluxes were slightly different. In particular, when the air-water exchange displayed net volatilization or approached equilibrium, the uncertainty ranges from both methods were comparable each other. However, when the trend presented net deposition (e.g., cases E03-3924 and 0n12-3503), the good estimation ranges from Monte Carlo simulation were obviously much wider than those from error propagation analysis. In particular, the lower boundaries of the exchange fluxes (or upper boundary of net deposition fluxes) from Monte Carlo simulation were much lower than those from error propagation analysis. A potential reason is that 
uncertainties in input data have different contributions to the uncertainty in the flux in different exchange trends (see below).

$$
\text { Generally speaking, both methods determine the uncertainty range of }
$$
air-water exchange flux of PCBs in the situations of net volatilization and approaching phase equilibrium well. However, Monte Carlo simulation is more precise, but more complex, than error propagation analysis. Error propagation analysis is a simple method to determine uncertainty in net volatilization flux, but is not recommended in net deposition situation, in which case Monte Carlo simulations should ideally be used.

Parameters sensitivity analysis. Probability distributions of air-water exchange flux were close to symmetrical distributions when air-water exchange approached equilibrium (see Figures S3.c and S3.d), while those in non-equilibrium situations showed positive skew (volatilization) or negative skew (deposition) distribution, as shown in Figure S3. Parameter sensitivity analysis can be employed to decide which parameters should be optimized or determined more accurately through further modeling or experimental studies. Hence, parameter sensitivity analysis was performed to study how the uncertainty in air-water exchange flux related to different sources of uncertainties in its input data, including atmospheric and aqueous concentrations, the Henry's law constant, ambient temperature and wind speed.

$$
\text { We selected the paired air and water passive samples collected in } 2012
$$
autumn at Cape Vincent (On12-3503) as a case study, because in this case all three air-water exchange situations (i.e. deposition, volatilization and equilibrium) were observed. Contributions to variance in air-water exchange fluxes, air-water fugacity ratios and the fluxes of selected PCBs are list in Table 1. 
Air-water fugacity ratios and probabilities of net deposition or volatilization indicate that primary trends of CB 28 and 52 were net deposition, those of CB 138 and 153 were net volatilization, and those of CB 101, 118 and 180 approached phase equilibrium. The parameter sensitivities were related with air-water exchange situation of PCBs, combining with Equation 4. When air-water exchange was approaching an equilibrium situation, uncertainty in air-water exchange flux was primarily controlled by the uncertainty in $H_{c}, C_{a}$ and $C_{w}$. Their assumed normal probability distributions would result in symmetrical probability distribution of the flux in Figures S3.c and d. In non-equilibrium situations, uncertainty in wind speed propagated largely to uncertainty in the flux and led to a large tail of its probability distribution (see Figure S3.a, b, e and f). The flux uncertainty was related to uncertainty in $C_{w}$ in net volatilization situation (e.g. CB 138 and 153), but related to uncertainties in $C_{a}$ and $H_{c}$ in net deposition situation (e.g. CB 28 and 52).

\section{Air-water exchange flux of total PCBs across the whole lakes. After} estimating site-specific air-water exchange fluxes of PCBs, we fitted PDFs of atmospheric and aqueous concentrations of PCBs and calculated probability distribution of air-water exchange flux across each entire lakes via Monte Carlo simulation (see Figure 4 and Table S3). Histograms of site-specific air-water exchange fluxes across Lakes Erie and Ontario are also illustrated in Figure 4. In both lakes, the calculated probability distributions via Monte Carlo simulation agreed well with the histograms. Across the whole Lake Erie, the calculated fluxes of total PCBs within a confidence level of $90 \%$ ranged from $-5.1 \mathrm{ng} \mathrm{m}^{-2}$ day $^{-1}$ (net deposition) to $52 \mathrm{ng} \mathrm{m}^{-2}$ day $^{-1}$ (net volatilization), and MLE, median and mean values were $0.78 \mathrm{ng} \mathrm{m}^{-2}$ day $^{-1}, 3.4 \mathrm{ng} \mathrm{m}^{-2}$ day $^{-1}$ and $11.7 \mathrm{ng} \mathrm{m}^{-2}$ day $^{-1}$, 
respectively. The probability of net volatilization $\left(F_{\mathrm{a} / \mathrm{w}}>0\right)$ was $84 \%$.

Contributions of aqueous and atmospheric concentrations, wind speed and temperature were $87 \%, 7 \%, 4 \%$ and $0.7 \%$ of the flux variability, respectively. A similar result was observed across the whole Lake Ontario. The flux of total PCBs (confidence level of 90\%) ranged from $-3.0 \mathrm{ng} \mathrm{m}^{-2}$ day-1 $^{-1}$ (net deposition) to $68 \mathrm{ng}$ $\mathrm{m}^{-2}$ day $^{-1}$ (net volatilization), and MLE, median and mean values were $0.53 \mathrm{ng} \mathrm{m}^{-2}$ day $^{-1}, 3.6 \mathrm{ng} \mathrm{m}^{-2}$ day $^{-1}$ and $13.6 \mathrm{ng} \mathrm{m}^{-2}$ day $^{-1}$, respectively. The probability of net volatilization was $87 \%$. Contributors are same with those in Lake Erie, accounting for $84 \%, 11 \%, 4 \%$ and $0.6 \%$ of the flux variability, respectively.

Gross volatilization loss of PCBs. If the probability distribution of air-water exchange flux mentioned above were acceptable, gross volatilization loss could be calculated by the product of surface area and arithmetic mean of the flux. Annual volatilization losses of total PCBs in the whole lake were $74 \mathrm{~kg}$ for Lake Erie and $63 \mathrm{~kg}$ for Lake Ontario (detailed in Table S3). Although the MLE of air-water exchange fluxes were frequently approached, the gross loss was significantly elevated by a few extremely large values of the volatilization flux (see Figure S1). It is noteworthy that the simulated probability distribution, to some extent, covered temporal and spatial variation of air-water exchange flux of PCBs across the whole lakes, especially under extreme conditions, e.g., gale.

Mass balance of PCBs. For the purpose of understanding the relative importance of air-water exchange of total PCBs, a mass balance of freely-dissolved PCBs in Lake Ontario was constructed. Annual input and output masses are presented in Figure 5 and Table S4. Compared mass loss via the St. Lawrence River ( $4.46 \pm 4.37 \mathrm{~kg}$ year-1 $^{-1}$, volatilization of PCBs from water to air (63 kg year-1) was the major loss pathway. Surprisingly, the annual loss was not 
balanced by the inputs from the Niagara River $\left(12.4 \pm 6.9 \mathrm{~kg}\right.$ year $\left.{ }^{-1}\right)$, other rivers $\left(\sim 0.6 \pm 0.3 \mathrm{~kg}\right.$ year $\left.^{-1}\right)$ and precipitation $\left(\sim 0.56 \pm 0.44 \mathrm{~kg}\right.$ year $\left.^{-1}\right)$. The parameters sensitivity analysis discussed above indicated that uncertainty in aqueous concentration is the primary contributor $(84 \%)$ to the variation of air-water exchange flux of PCBs across Lake Ontario. Our previous study suggested that river discharge and localized influences likely dominated spatial distribution of aqueous PCBs in both lakes. ${ }^{8}$ Hence, the reason for more PCBs volatilizing from the lake surface than entering from rivers and deposition is probably attributed to uninvolved contributions from other large tributaries (e.g., rivers of Humber, Credit and Nappanee), land based sources (e.g., waste water treatment plant and urban runoff) and (resuspended) sediment releasing PCBs back to water phase. Nevertheless, further effort is warranted to evaluate their contributions.

\section{IMPLICATIONS}

The estimation of uncertainty in air-water exchange fluxes of PCBs is a challenge because many measurement with considerable uncertainty are involved. Besides the filter bias of active sampling, in theory, there is not significant difference in calculation of air-water flux at specific sites for active and passive sampling, if PCBs reached equilibrium between passive sampler and ambient air (or water). Air-water fluxes across the lower Great Lakes are constantly changing over time and space. Yet the high cost of active sampling significantly restricts our ability to assess the spatial variation of air-water exchange flux at a large scale, such as across Lakes Erie and Ontario. The deployment of passive sampler at a high geospatial resolution could overcome these restrictions. In theory, passive sampling technology can more precisely evaluate the direction of air-water 
exchange of lighter PCBs because of lower relative uncertainty in \%equilibrium. Although Monte Carlo simulations were successfully used to estimate uncertainty in air-water exchange of PCBs across the whole lakes, some limitations affected also this study. For example, few samplers were deployed in the open lake and along the Canadian shore. In addition, temperature dependence of atmospheric concentration of PCBs failed to be defined in the Monte Carlo simulation. Fugacity and net flux are related to ambient temperature. Increasing temperatures enhance the volatilization flux due to temperature corrections to the partitioning coefficient between air and water (major) and water-side mass transfer coefficient (minor). Spatial variations in wind speed over both lakes were ignored in this case, assuming that they were minor over open-lake areas, which makes up most of the total surface area of the Great Lakes.

\section{ASSOCIATED CONTENT}

\section{Supporting Information}

Detailed information on error propagation analysis and Monte Carlo simulation can be found along with calculated gross volatilization loss and mass balance of PCBs in the lakes. This material is available free of charge via the Internet at Http://pubs.acs.org.

\section{AUTHOR INFORMATION}

\section{Corresponding Author.}

*E-mail: lohmann@gso.uri.edu

\section{Notes}


The authors declare no competing financial interest.

\section{ACKNOWLEDGEMENTS}

We acknowledge funding from EPA's Great Lakes Restoration Initiative Award GLAS No. 00E00597-0 (Project Officer Todd Nettesheim) supporting passive sampler research in the Great Lakes, the Foundation of State Key Laboratory of Pollution Control and Resource Reuse (No.: PCRRY15013) and the Shanghai Science and Technology Commission (No. 16ZR1438100). We thank Dave Adelman (URI) and our cast of volunteers for passive sampler deployments around Lakes Erie and Ontario and the field staff of the Emergencies, Operational Analytical Laboratories, and Research Support group (Environment Canada Burlington) for open-lake deployments, and the Ontario Ministry of the Environment for near-shore deployments along Lake Ontario.

\section{REFERENCES:}

1. Melymuk, L.; Robson, M.; Csiszar, S. A.; Helm, P. A.; Kaltenecker, G.; Backus, S.; Bradley, L.; Gilbert, B.; Blanchard, P.; Jantunen, L. From the city to the lake: Loadings of PCBs, PBDEs, PAHs and PCMs from Toronto to Lake Ontario. Environ. Sci. Technol. 2014, 48 (7), 3732-3741.

2. Salamova, A.; Venier, M.; Hites, R. A. Revised Temporal Trends of Persistent Organic Pollutant Concentrations in Air around the Great Lakes. Environmental Science \& Technology Letters 2015, 2 (2), 20-25.

3. Binational.net Canada and the United States Designate the First Set of Chemicals of Mutual Concern. https://binational.net/2016/05/31/cmcdesig-pcpmdesig/

4. Eisenreich, S. J.; Looney, B. B.; Thornton, J. D. Airborne organic contaminants in the Great Lakes ecosystem. Environ. Sci. Technol. 1981, 15 (1), 30-38.

5. Jiménez, J. C.; Dachs, J.; Eisenreich, S. J. Chapter 8 - Atmospheric Deposition of POPs: Implications for the Chemical Pollution of Aquatic Environments. Comprehensive Analytical Chemistry 2015, 67, 295-322.

6. Bidleman, T. F.; Mcconnell, L. L. A Review of Field Experiments to Determine Air-Water Gas-Exchange of Persistent Organic Pollutants. Sci. Total. Environ. 1995, 159 (2-3), 101-117.

7. Hornbuckle, K. C.; Jeremiason, J. D.; Sweet, C. W.; Eisenreich, S. J. Seasonal-Variations in 
Air-Water Exchange of Polychlorinated-Biphenyls in Lake-Superior. Environ. Sci. Technol. 1994, 28 (8), 1491-1501.

8. Liu, Y.; Wang, S.; McDonough, C. A.; Khairy, M.; Muir, D. C.; Helm, P. A.; Lohmann, R. Gaseous and Freely-Dissolved PCBs in the Lower Great Lakes Based on Passive Sampling: Spatial Trends and Air-Water Exchange. Environ. Sci. Technol. 2016, 50 (10), 4932-9.

9. Ruge, Z.; Muir, D.; Helm, P.; Lohmann, R. Concentrations, Trends, and Air-Water Exchange of PAHs and PBDEs Derived from Passive Samplers in Lake Superior in 2011. Environ. Sci. Technol. 2015, 49 (23), 13777-13786.

10.Schwarzenbach, R. P.; Gschwend, P. M.; Imboden, D. M. Environmental Organic Chemistry (2nd edition). Wiley Interscience: USA, 2002.

11.Tidwell, L. G.; Allan, S. E.; O'Connell, S. G.; Hobbie, K. A.; Smith, B. W.; Anderson, K. A. Polycyclic Aromatic Hydrocarbon (PAH) and Oxygenated PAH (OPAH) Air-Water Exchange during the Deepwater Horizon Oil Spill. Environ. Sci. Technol. 2015, 49 (1), 141-149.

12.Gigliotti, C. L.; Brunciak, P. A.; Dachs, J.; Glenn, T. R.; Nelson, E. D.; Totten, L. A.; Eisenreich, S. J. Air-water exchange of polycyclic aromatic hydrocarbons in the New York-New Jersey, Usa, Harbor Estuary. Environ. Toxicol. Chem. 2002, 21 (2), 235-244.

13.Swackhamer, D. L.; Schottler, S.; Pearson, R. F. Air-water exchange and mass balance of toxaphene in the great lakes. Environ. Sci. Technol. 1999, 33 (21), 3864-3872.

14.Nelson, E. D.; McConnell, L. L.; Baker, J. E. Diffusive exchange of gaseous polycyclic aromatic hydrocarbons and polychlorinated biphenyls across the air-water interlace of the Chesapeake Bay. Environ. Sci. Technol. 1998, 32 (7), 912-919.

15.Qin, N.; He, W.; Kong, X. Z.; Liu, W. X.; He, Q. S.; Yang, B.; Ouyang, H. L.; Wang, Q. M.; Xu, F. L. Atmospheric partitioning and the air-water exchange of polycyclic aromatic hydrocarbons in a large shallow Chinese lake (Lake Chaohu). Chemosphere 2013, 93 (9), 1685-1693.

16.Blanchard, P.; Audette, C. V.; Hulting, M. L.; Basu, I.; Brice, K.; Backus, S.; Dryfhout-Clark, H.; Froude, F.; Hites, R.; Nielson, M.; Wu, R. Atmospheric Deposition of Toxic Substances to the Great Lakes: IADN Results through 2005. US EPA and Environment Canada, US EPA 905-R-08-001.: 2008; p 226.

17.Rowe, M. D.; Perlinger, J. A. Micrometeorological measurement of hexachlorobenzene and polychlorinated biphenyl compound air-water gas exchange in Lake Superior and comparison to model predictions. Atmos. Chem. Phys. 2012, 12 (10), 4607-4617.

18.Fang, M. D.; Ko, F. C.; Baker, J. E.; Lee, C. L. Seasonality of diffusive exchange of polychlorinated biphenyls and hexachlorobenzene across the air-sea interface of Kaohsiung Harbor, Taiwan. Sci. Total. Environ. 2008, 407 (1), 548-565.

19.Cheng, J. O.; Ko, F. C.; Lee, C. L.; Fang, M. D. Air-water exchange fluxes of polycyclic aromatic hydrocarbons in the tropical coast, Taiwan. Chemosphere 2013, 90 (10), 2614-2622.

20.Lin, T.; Guo, Z.; Li, Y.; Nizzetto, L.; Ma, C.; Chen, Y. Air-Seawater Exchange of Organochlorine Pesticides along the Sediment Plume of a Large Contaminated River. Environ. Sci. Technol. 2015, 49 (9), 5354-62.

21.Wang, X.; Nagpure, A. S.; DeCarolis, J. F.; Barlaz, M. A. Characterization of Uncertainty in Estimation of Methane Collection from Select U.S. Landfills. Environ. Sci. Technol. 2015, 49 
(3), 1545-1551.

22.Venier, M.; Hites, R. A. Atmospheric deposition of PBDEs to the Great Lakes featuring a Monte Carlo analysis of errors. Environ. Sci. Technol. 2008, 42 (24), 9058-64.

23.Khairy, M.; Muir, D.; Teixeira, C.; Lohmann, R. Spatial Distribution, Air-Water Fugacity Ratios and Source Apportionment of Polychlorinated Biphenyls in the Lower Great Lakes Basin. Environ. Sci. Technol. 2015, 49 (23), 13787-97.

24.Lohmann, R.; Muir, D. Global Aquatic Passive Sampling (AQUA-GAPS): Using Passive Samplers to Monitor POPs in the Waters of the World. Environmental Science \& Technology 2010, 44 (3), 860-864.

25.Khairy, M.; Muir, D.; Teixeira, C.; Lohmann, R. Spatial Trends, Sources, and Air-Water Exchange of Organochlorine Pesticides in the Great Lakes Basin Using Low Density Polyethylene Passive Samplers. Environ. Sci. Technol. 2014, 48 (16), 9315-9324.

26.Blanchard, P.; Audette, C. V.; Hulting, M. L.; Basu, I.; Brice, K. A.; Backus, S. M.; Dryfhout-Clark, H.; Froude, F.; Hites, R. A.; Neilson, M. Atmospheric deposition of toxic substances to the Great Lakes: IADN results through 2005. Environment Canada Burlington: 2008; p 226.

27.Mackay, D. Multimedia environmental models: the fugacity approach. CRC press: 2001.

28.Wang, Y.; Luo, C. L.; Wang, S. R.; Liu, J. W.; Pan, S. H.; Li, J.; Ming, L. L.; Zhang, G.; Li, X. D. Assessment of the Air-Soil Partitioning of Polycyclic Aromatic Hydrocarbons in a Paddy Field Using a Modified Fugacity Sampler. Environ. Sci. Technol. 2015, 49 (1), 284-291.

29.Luo, X. L.; Zheng, Y.; Lin, Z. R.; Wu, B.; Han, F.; Tian, Y.; Zhang, W.; Wang, X. J. Evaluating potential non-point source loading of PAHs from contaminated soils: A fugacity-based modeling approach. Environ. Pollut. 2015, 196, 1-11.

30.Castro-Jimenez, J.; Berrojalbiz, N.; Wollgast, J.; Dachs, J. Polycyclic aromatic hydrocarbons (PAHs) in the Mediterranean Sea: Atmospheric occurrence, deposition and decoupling with settling fluxes in the water column. Environ. Pollut. 2012, 166, 40-47.

31.Zhong, G. C.; Xie, Z. Y.; Moller, A.; Halsall, C.; Caba, A.; Sturm, R.; Tang, J. H.; Zhang, G.; Ebinghaus, R. Currently used pesticides, hexachlorobenzene and hexachlorocyclohexanes in the air and seawater of the German Bight (North Sea). Environ. Chem. 2012, 9 (4), 405-414.

32.Mulder, M. D.; Heil, A.; Kukucka, P.; Klanova, J.; Kuta, J.; Prokes, R.; Sprovieri, F.; Lammel, G. Air-sea exchange and gas-particle partitioning of polycyclic aromatic hydrocarbons in the Mediterranean. Atmos. Chem. Phys. 2014, 14 (17), 8905-8915.

33.Jantunen, L. M.; Wong, F.; Gawor, A.; Kylin, H.; Helm, P. A.; Stern, G. A.; Strachan, W. M. J.; Burniston, D. A.; Bidleman, T. F. 20 Years of Air-Water Gas Exchange Observations for Pesticides in the Western Arctic Ocean. Environ. Sci. Technol. 2015, 49 (23), 13844-13852.

34.Bruhn, R.; Lakaschus, S.; McLachlan, M. S. Air/sea gas exchange of PCBs in the southern Baltic Sea. Atmos. Environ. 2003, 37 (24), 3445-3454.

35.Lammel, G.; Audy, O.; Besis, A.; Efstathiou, C.; Eleftheriadis, K.; Kohoutek, J.; Kukucka, P.; Mulder, M. D.; Pribylova, P.; Prokes, R.; Rusina, T. P.; Samara, C.; Sofuoglu, A.; Sofuoglu, S. C.; Tasdemir, Y.; Vassilatou, V.; Voutsa, D.; Vrana, B. Air and seawater pollution and air-sea gas exchange of persistent toxic substances in the Aegean Sea: spatial trends of PAHs, PCBs, OCPs and PBDEs. Environ. Sci. Pollut. R. 2015, 22 (15), 11301-11313. 
36.Lohmann, R.; Gioia, R.; Jones, K. C.; Nizzetto, L.; Temme, C.; Xie, Z.; Schulz-Bull, D.; Hand, I.; Morgan, E.; Jantunen, L. Organochlorine Pesticides and PAHs in the Surface Water and Atmosphere of the North Atlantic and Arctic Ocean. Environ. Sci. Technol. 2009, 43 (15), 5633-5639.

37.Zhong, G.; Xie, Z.; Cai, M.; Moller, A.; Sturm, R.; Tang, J.; Zhang, G.; He, J.; Ebinghaus, R. Distribution and air-sea exchange of current-use pesticides (CUPs) from East Asia to the high Arctic Ocean. Environ. Sci. Technol. 2012, 46 (1), 259-67.

38.Fang, M. D.; Lee, C. L.; Jiang, J. J.; Ko, F. C.; Baker, J. E. Diffusive exchange of PAHs across the air-water interface of the Kaohsiung Harbor lagoon, Taiwan. J. Environ. Manage. 2012, $110,179-87$. 
617

618

619

620

621

\begin{tabular}{cccccccc}
\hline Variables & PCB28 & PCB52 & PCB101 & PCB118 & PCB138 & PCB153 & PCB180 \\
\hline (Parameter sensitivity & analysis) & & & & & \\
PCB in air & $\mathbf{- 0 . 2 8}$ & $\mathbf{- 0 . 2 6}$ & $\mathbf{- 0 . 2 5}$ & $\mathbf{- 0 . 3 9}$ & -0.07 & -0.09 & $\mathbf{- 0 . 2 0}$ \\
$\mathrm{H}_{\mathrm{c}}$ & $\mathbf{0 . 6 0}$ a & $\mathbf{0 . 5 5}$ & $\mathbf{0 . 5 8}$ & $\mathbf{0 . 5 2}$ & 0.15 & 0.22 & $\mathbf{0 . 3 5}$ \\
PCB in water & 0.08 & 0.10 & $\mathbf{0 . 5 2}$ & $\mathbf{0 . 5 0}$ & $\mathbf{0 . 5 5}$ & $\mathbf{0 . 5 5}$ & $\mathbf{0 . 5 9}$ \\
Temperature & -0.12 & -0.13 & -0.01 & -0.01 & 0.10 & 0.09 & 0.06 \\
Wind Speed & $\mathbf{- 0 . 5 5}$ & $\mathbf{- 0 . 6 1}$ & 0.03 & 0.09 & $\mathbf{0 . 6 4}$ & $\mathbf{0 . 6 0}$ & $\mathbf{0 . 4 5}$
\end{tabular}

(Estimation of air-water exchange situation)

\begin{tabular}{cccccccc}
$\log \left(f_{\mathrm{a}} / f_{\mathrm{w}}\right)^{\mathrm{b}}$ & 0.34 & 0.44 & -0.04 & -0.09 & -0.83 & -0.98 & -0.53 \\
Flux $^{\mathrm{c}}$ & -0.54 & -0.23 & 0.01 & 0.02 & 0.1 & 0.09 & 0.02 \\
Certainty $^{\mathrm{d}}$ & $95 \%$ & $97 \%$ & $51 \%$ & $56 \%$ & $92 \%$ & $94 \%$ & $83 \%$ \\
Situation & Deposition & Equilibrium & Volatilization & Equilibr. \\
\hline
\end{tabular}

622 a, Major contributors to the variance are marked by Bold.

623 b, Table S2 in the Supporting Information indicated the range of ratios where air water

624 exchange does not significant deviate from equilibrium.

625 c, Negative presents for deposition and positive for volatilization, unit: $\mathrm{ng} \mathrm{m}^{-2}$ day $^{-1}$;

626 d, Certainty of net deposition or net volatilization, probability distributions of the fluxes are

627 illustrated in Figure S3; 
629 TOC

630 (Size: $8.47 \mathrm{~cm} \mathrm{x} 4.24 \mathrm{~cm}$ )

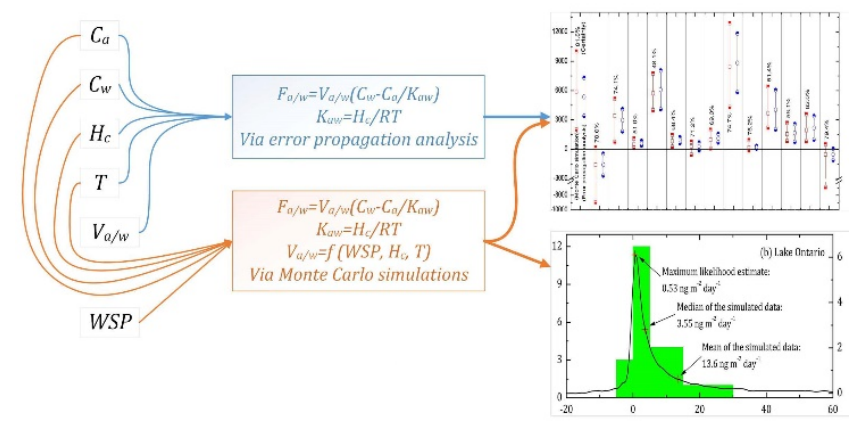

631 


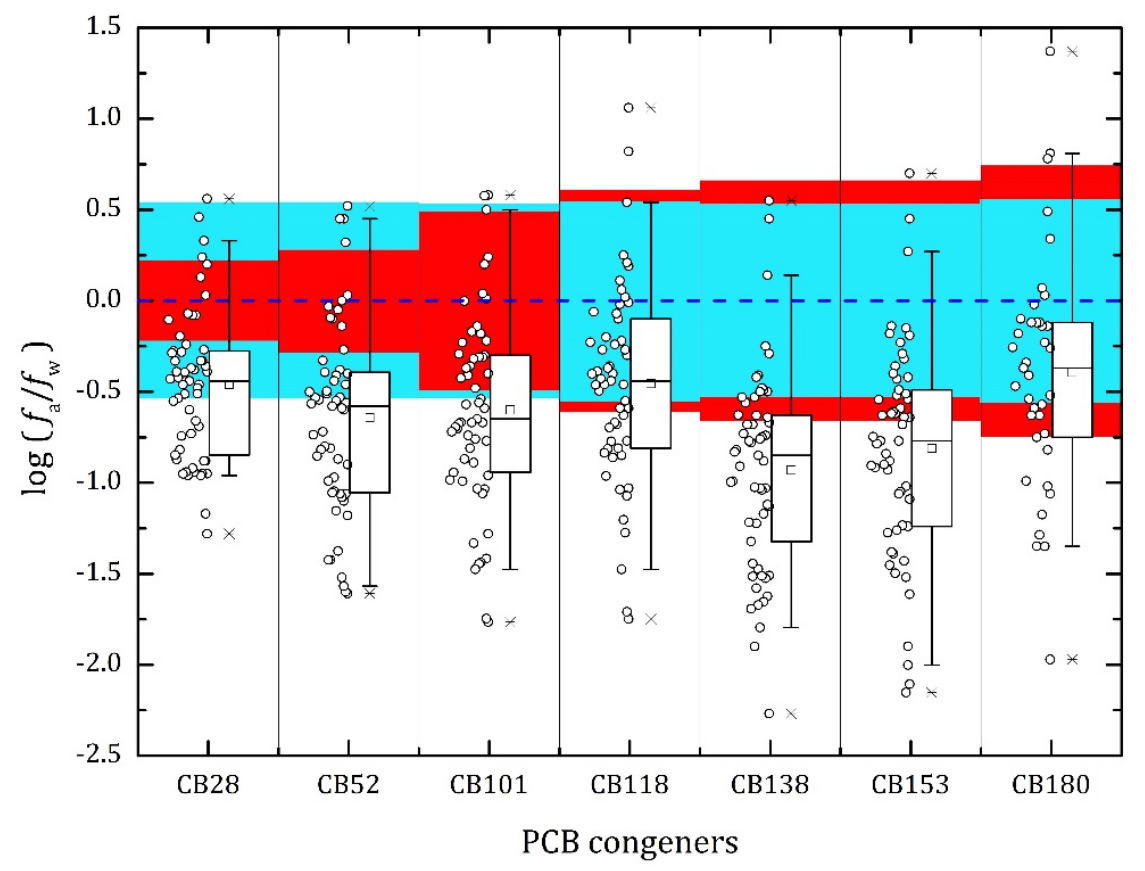

632

633

634

635

636

637

638

Figure 1. Log-transformed air-water fugacity ratios of selected 7 PCBs. Blue dash line presents equilibrium between air and water theoretically. Red and cyan regions indicate the range that air-water exchange does not significant deviate from equilibrium, based on Equations 7 and 8, respectively. 


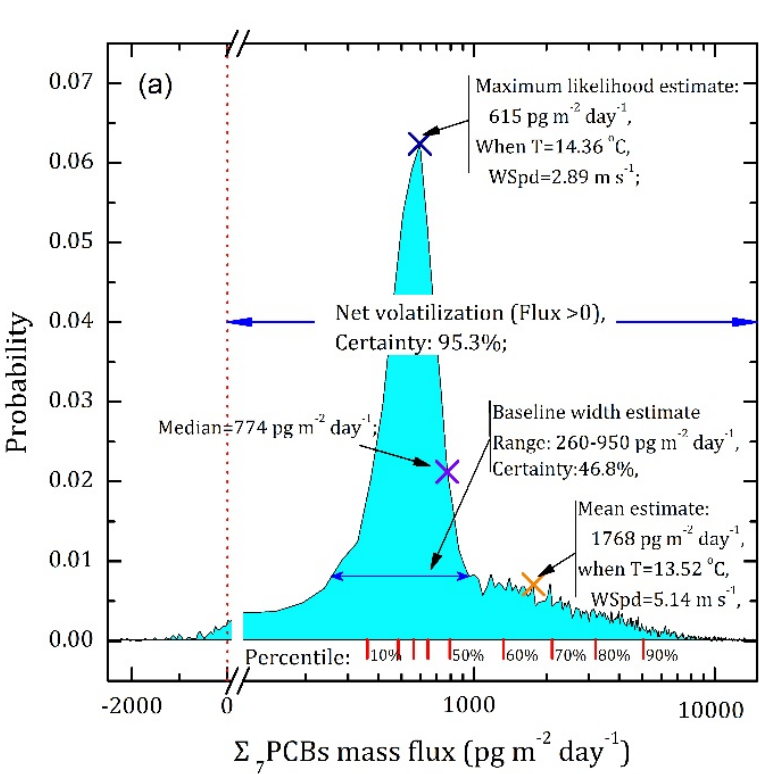

641

642

643

644

645

646

647

648

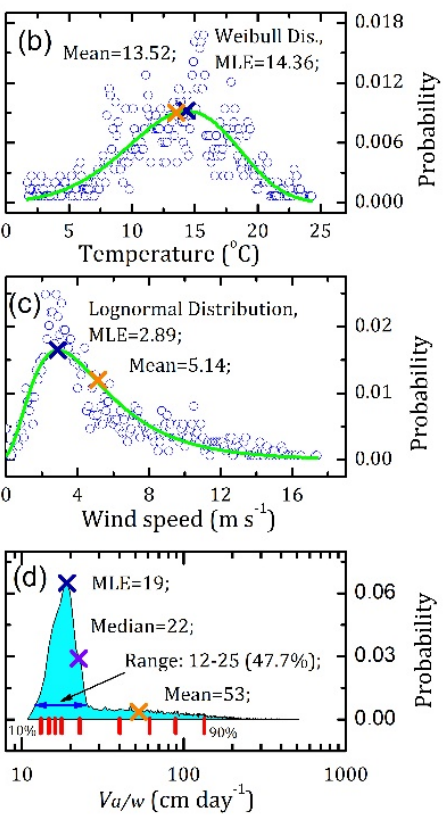

Figure 2. Total air-water exchange flux of 7 selected PCBs from Monte Carlo simulation. Black, orange and violet crosses present maximum likelihood estimation (MLE), arithmetic mean and median values, respectively. Temperature followed a Weibull distribution, and wind speed was fitted well by a lognormal distribution. 


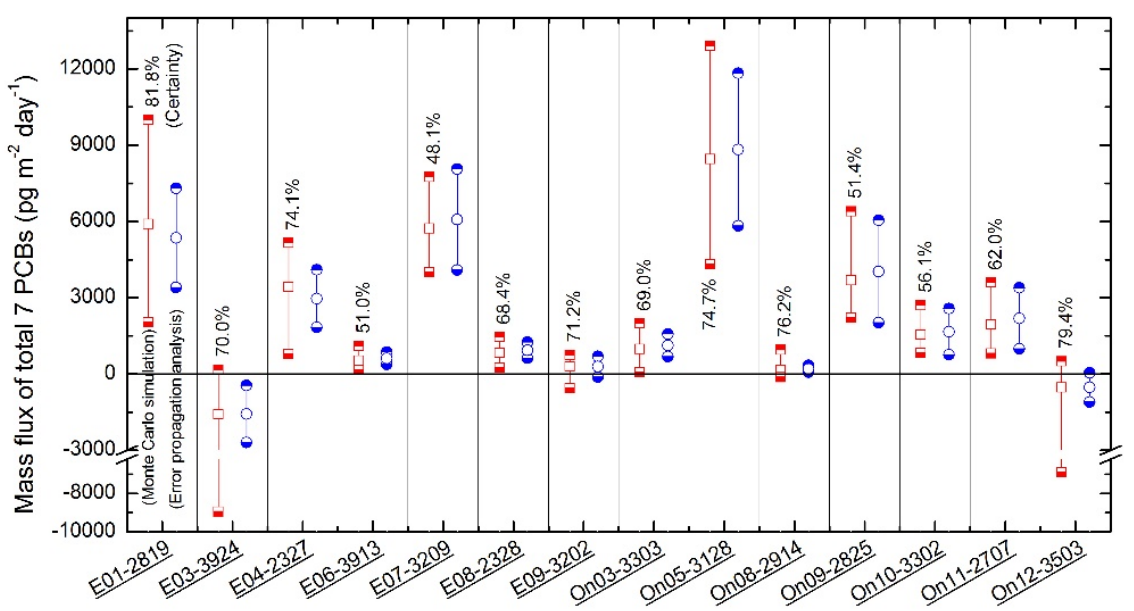

650

651 Figure 3. Best estimates (open) and uncertainty ranges (half solid) of air-water exchange 652 flux of $\Sigma_{7} \mathrm{PCBs}$ for fourteen selected samples. Certainties in good estimation range of the flux and uncertainty ranges between red squares were determined based on Monte Carlo simulation. The uncertainty ranges between blue circles were quantified by error propagation analysis. 


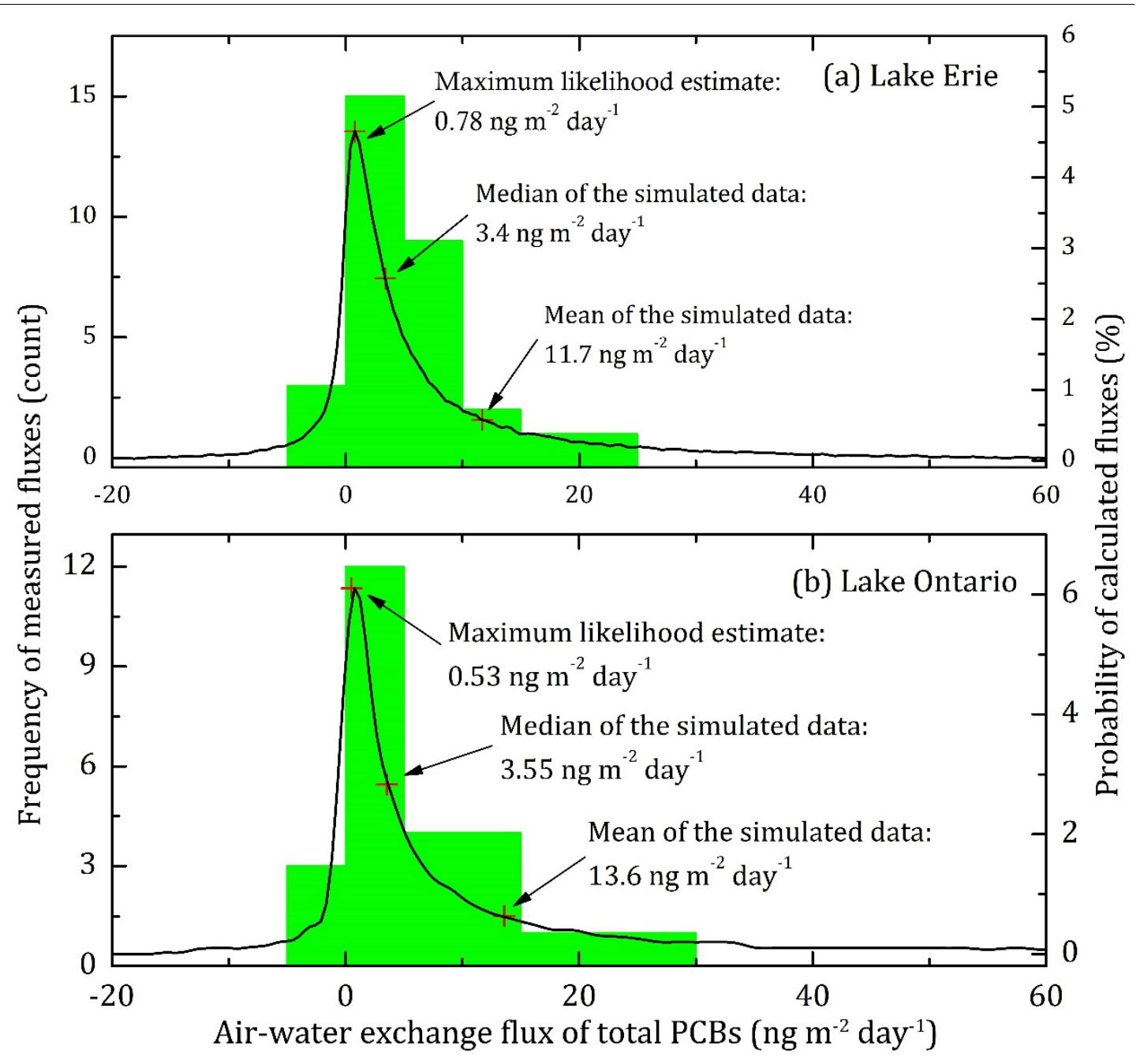

Figure 4. Monte Carlo-simulated probability distribution and measured frequency histogram of air-water exchange flux of total PCBs across Lake Erie (a) and Ontario (b). 


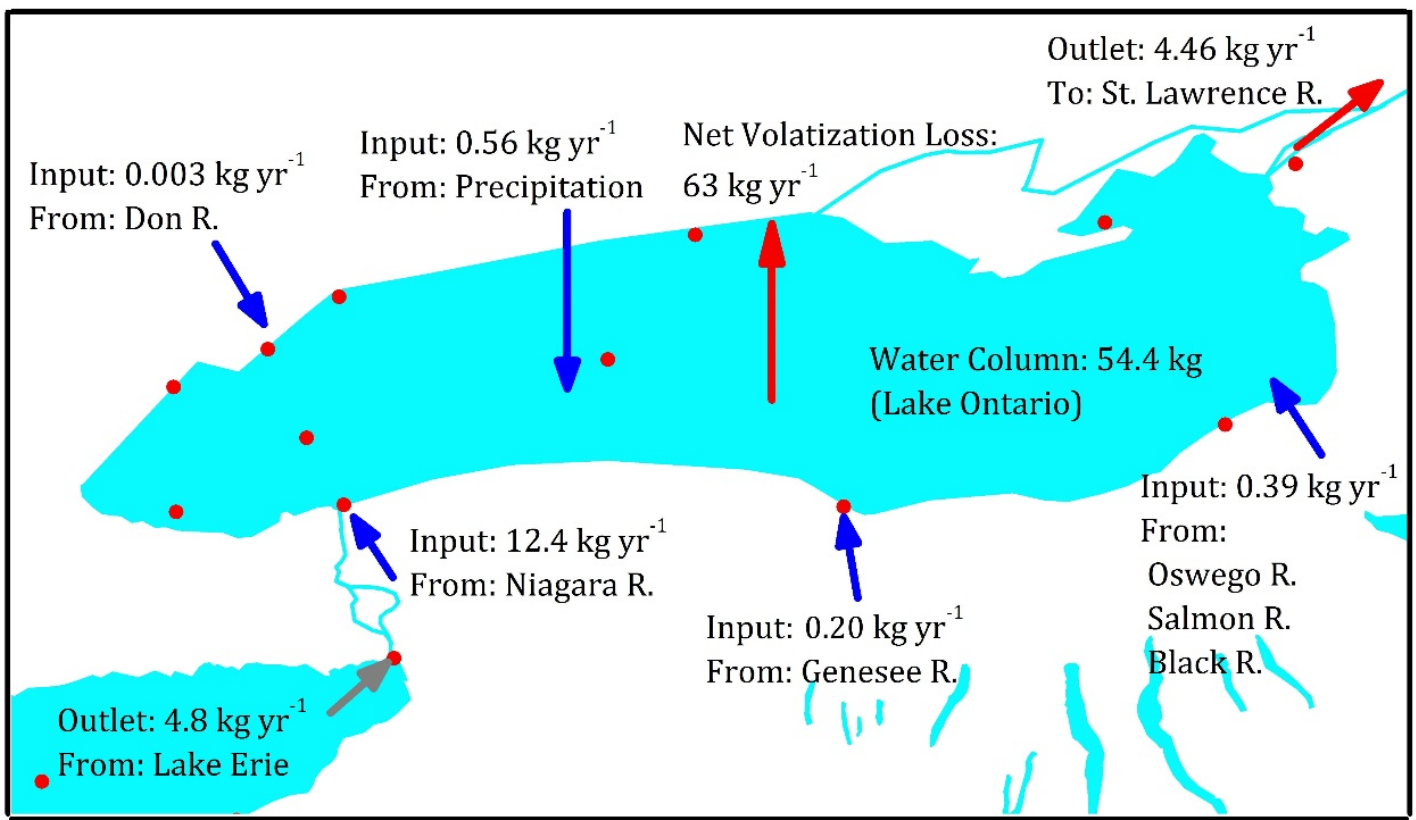

665

666

667

668

669

Figure 5. Mass balance of PCBs in Lake Ontario. Blue and red arrows present annual input and output of freely-dissolved PCBs. 